University of South Florida

DIGITAL COMMONS

Digital Commons @ University of

@ UNIVERSITY OF SOUTH FLORIDA

South Florida

Tampa Library Faculty and Staff Publications

Tampa Library

2017

\title{
The Invisible Employee: Success and Fragility of Automating Interlibrary Loan
}

LeEtta Schmidt

University of South Florida, Imschmidt@usf.edu

Follow this and additional works at: https://digitalcommons.usf.edu/tlib_facpub

Part of the Library and Information Science Commons

\section{Scholar Commons Citation}

Schmidt, LeEtta, "The Invisible Employee: Success and Fragility of Automating Interlibrary Loan" (2017). Tampa Library Faculty and Staff Publications. 15.

https://digitalcommons.usf.edu/tlib_facpub/15

This Article is brought to you for free and open access by the Tampa Library at Digital Commons @ University of South Florida. It has been accepted for inclusion in Tampa Library Faculty and Staff Publications by an authorized administrator of Digital Commons @ University of South Florida. For more information, please contact digitalcommons@usf.edu. 
RUNNING HEAD: Invisible Employee

The Invisible Employee: success and fragility of automating interlibrary loan

LeEtta M. Schmidt

University of South Florida, Tampa Library

This is an Accepted Manuscript of an article published by Taylor \& Francis in the Journal of Interlibrary Loan, Document Delivery \& Electronic Reserve on 17 May 2018, available online: https://dx.doi.org/10.1080/1072303X.2018.1465011 
RUNNING HEAD: Invisible Employee

\section{Abstract:}

Libraries and their interlibrary loan departments have enacted different methods for improving processes and services to create greater efficiency and less waste. Techniques range from holistic, and expansive process improvement projects to leveraging the ability of request management systems to automate processes and services successfully. This article explores the effect of automation on the output of a sample interlibrary loan department and points out possible challenges that this automation success may create in the future.

Keywords: Interlibrary loan departments, automation, process improvement, ILLiad 
RUNNING HEAD: Invisible Employee

\section{INTRODUCTION}

Libraries and interlibrary loan departments of many types exist at a transition point where some have systems that provide automation of staff tasks to improve efficiencies and service, and yet some other libraries have not, or have not made extensive use of the automation capabilities. The extent of automating tasks among libraries also varies from relatively small batch processes to more aggressive applications of system automation. To what extent a library may employ automation will depend as much on the resources and demands upon the department as it does on the expertise developed by individual staff or technology support.

It has been well documented that libraries turned to the business world to find strategies for confronting commonly experienced situations of lowered funding, lowered staffing, increased patron demands, and changing technology (Nozero \& Vaughan, 2000; Voyles, Dols, \& Knight, 2009; Lepmets, McBride \& Ras, 2012; Fox, 2016). Process improvement, Total Quality Management (TQM), Six Sigma, re-engineering, iterative, and Agile development rose and fell in the literature as ways that libraries could cut waste processes, increase efficiency, trim costs, and satisfy patrons. As improvement systems they are holistic, all encompassing, time consuming, and rigorous. Libraries undertaking such evaluations must accept the interconnectedness of all library processes and services, often confronting departmental divides that hamper progress. Perhaps this is the reason why reports of libraries implementing such systems are relatively low (Voyles, Dols \& Knight, 2009). However, "quality improvement literature helps to frame libraries not as a place or a service, but as a system made up of a number of processes. These processes are made up of a number of steps "(Veldof, 
RUNNING HEAD: Invisible Employee

1999 p34). Each of these processes, and each of the steps that make up the processes, can be made more efficient to the benefit of the whole without undertaking a whole process improvement plan for the library. This article will cover how one interlibrary loan department improved services by examining internal processes with an eye towards improvement and automation.

\section{LITERATURE REVIEW}

Libraries use a variety of systems and processes to manage library activities and services on a daily basis. These processes, like those involved in the acquisitions of materials or the handling of license agreements may be extremely complex and perhaps unaltered over long periods of time. As Fox noted in his overview of process improvement possibilities in libraries, cataloging, maintaining bibliographic records and materials, acquisitions, circulation and more are all process-based activities for which operational goals and focus may have shifted over time (2016). Patron demands and emphasis on service have also evolved over time, and often it is this that drives improvement projects. Patron demands accounted for at least half of the reasoning behind the University of Arizona's decision to improve document delivery services. This desire to fulfill patron's "increased demand of research, [and] the need to receive articles faster" was coupled with a library goal of reducing costs and improving overall efficiencies (Voyles, Dols, \& Knight, 2009 p76). Similarly Kenefick \& DeVito have found that a library user's focus on "instant gratification, convenient tools, and exceptional customer service" have made timeliness a primary goal of interlibrary loan $(2013, \mathrm{p} 160)$. This observation is echoed by Pritting \& Jones who point out that resource sharing has increased "as the economic environment of libraries has changed," and that this increase in service use has coincided with 
RUNNING HEAD: Invisible Employee

an increase in delivery expectations $(2015, \mathrm{p} 28)$.

Yet, interlibrary loan is also a library service with complex processes and multiple interlinked systems that result in it being extremely labor intensive for library staff (Munson \& Thompson, 2018 p 18). Often it is left in the hands of a few specialized personnel, while colleagues in nearby and related departments have little to no idea how it is accomplished. In the initial analysis of the document delivery service, University of Arizona library staff found that lack of individual department staffing over weekends was a primary component of a below acceptable turnaround (Voyles, Dols, \& Knight, 2009). Whether included in the cost assessment of a service or improvement plan, staff time and activity also represent a huge monetary investment in both daily operations and process improvement projects. Nozero and Vaughan have noted that rising unit costs, dwindling financial resources, and increased information availability are putting academic libraries in precarious positions as they attempt to respond to the changing environment (2000). Process improvements can help increase the efficiency and the cost effectiveness of daily operations but may require the investment of staff time and resources as attention is turned to completely rethinking the way departmental activities are usually done (Veldof, 1999). Additionally, after any initial process improvement project, processes need to "continuously ... undergo changes and refinements in order to increase their ability to deal with requirements and expectations (Lepments, McBride \& Ras, 2012 p1440)."

Libraries have experimented with many different methods of process improvement from the business world to achieve goals of higher efficiency, turn around, and lower cost. At the University of Arizona, TQM and Six Sigma were used to inform a project that sought to eliminate waste processes in the document delivery department (Voyles, Dols, \& Knight, 2009). 
RUNNING HEAD: Invisible Employee

Nozero and Vaughan specifically looked at re-engineering - a method whereby existing processes are completely scrapped and off the table in favor of starting a new and improved process from scratch. This is unique from process improvement that looks at existing processes for potential changes that would favorably evolve the process over time (Nozero \& Vaughan, 2000). Process improvement looks to make an improvement in line with organizational goals, however, there is often no definite way to align the two (Lepmets, McBride \& Ras, 2012), so practitioners are often left to establish connections themselves. Focusing too much on method can also make a sometimes complex process improvement project even more time consuming. As Fox notes, focus on method can become its own obsession:
"It has become almost an obsession in modern culture to perseverate on method. There are many synonyms for this obsession: process improvement, process maturity, continuous improvement, business performance improvement, total productive maintenance, quality management, etc. A contemporaneous bevy of seminars and programs designed to help management teams to enable process improvement has also been spawned that enables this obsession." (Fox, 2016 p130)

However, methods like those mentioned are developed to help avoid the common pitfalls of attempting a process improvement plan in a vacuum. Processes within an organization are often connected with sophisticated systems and cross departmental interactions that make it impossible to completely overhaul the processes of one department without impacting those of another (Lepmets, McBride \& Ras, 2012). This enormity of effect can seem overwhelming to some libraries and deter them from embarking on process improvement schemes at all. While the interconnectedness of processes and services should be present in the mind, as Veldof mentioned, each process is made up of a series of steps 
RUNNING HEAD: Invisible Employee

(1999), and changes to these steps could have an effect on the whole process without adversely affecting the whole library. Instead, improvements and efficiencies can be added to processes in stages. The Information Delivery Services (IDS) project has created a variety of different tools that other libraries can use to make their operation more efficient by utilizing the abilities of existing software systems and services subscribed to by many libraries. Specifically, the IDS project leverages the ability of the ILLiad resource sharing system to accept server side add-ons that will send commands based on information in incoming requests to move those requests without staff needing to take action (Pritting \& Jones, 2015).

In all plans to improve process efficiencies it is important to obtain a full and clear view of how current processes work and why they are in place; while external and fresh views may be needed to find new opportunities for change, the staff members intimately involved with the processes must also be included to give context to operational tasks (Nozero \& Vaughan, 2000). Additionally, customer needs and demands must be factored in before embarking on improvement plans that may mean nothing to the end user and/or not align with institutional goals and values (Lepmets, McBride \& Ras, 2012; Veldof, 1999).

The results of the process improvement plans reported in the literature are usually encouraging. At the University of Arizona, cross training circulation staff to address document delivery questions during the evening and weekend had a profound impact on turn-around (Voyles, Dols, \& Knight, 2009). By implementing IDS tools, developed to decrease the amount of requests staff have to handle, or the amount of handling staff need to apply to each request, resulted in a general decrease in the costs of interlibrary loan fulfillment at IDS libraries (Pritting \& Jones, 2015). Patron satisfaction is another possible, yet harder to measure, benefit of 
RUNNING HEAD: Invisible Employee

improvement plans. Kenefick and DeVito reported that services that mirror a patron's experiences with other, often immediate, web services tended to produce higher patron satisfaction levels and that unmediating interlibrary loan requests was "one of the most promising ways to achieve faster turnaround times," regardless of the possible small errors that may occur (Kenefick \& DeVito, 2013 p161). In these examples, leveraging the ability of the request management systems in interlibrary loan can present the opportunity to improve processes and services successfully without investing in a larger, holistic process improvement plan. Mark Dehmlow points out a trend in technology optimization and automation that should also be taken into account by those embarking on process improvements that involve system add-ons and alterations. The staff who develop the specialized skills to create these system changes also create an environment where specialized staff will be needed to maintain the improved processes. This requires libraries to include and make time for training within their plans and amidst other demands (2017).

HISTORY

The University of South Florida (USF) Tampa library ILL department acquired ILLiad in 1999. At that time, the system did much to simplify the complicated process of paperwork that ILL required. During USF's first few years with ILLiad, requesting was high and staffing was equally high as the number of staff in the department was a hold-over from days with a paper system. Staff were put to use managing the transition to ILLiad and the more than doubled patron requests from 1998. Within five years, however, request levels dropped by $33 \%$ coinciding with a natural trimming of staffing levels in the department due to retirements and promotions. A lean department of 4.5 personnel expanded services between $2009-2012$ to 
RUNNING HEAD: Invisible Employee

include an on campus document delivery service, purchase on demand through ILL, request referral to the Special Collections and acquisitions systems, request receipt from the Reserves system, and branch library operations. During, and perhaps due to, this expansion in services, requests levels rebounded $18 \%$. ILL staff also noticed an increase in the number of requests that required special handling because of complexity or rarity of materials.

Similar to many interlibrary loan departments in academic libraries, USF Tampa library interlibrary loan found itself in need of providing more or better services to suit user needs with little to no extra resources. USF ILL's methods of dealing with a heavy workload and high turnover commitment were common ones. While minimum quality standards were maintained, sacrifices had to be made in order to balance resources and demand. Extra editing of scanned documents and timely follow-up on request statuses, like overdues, were examples of processes typically abandoned in favor of a focus on general turn-around goals. While looking for ways to absorb or offset the workload with the tools available, the ILL department discovered plenty of additional process steps that seemed ripe for elimination. These steps were mostly wholly internal and would not affect any other library department, however, care had to be taken to make sure any changes to processing within ILLiad did not affect the other library sites included in USF's ILLiad installation, as each site was run independently. Improvements were initially manager lead with encouragements to staff to be mindful of their daily processes and question whether what they were doing was absolutely necessary. Eventually a collection of internal steps were shaved from daily interlibrary loan processing. IMPROVEMENTS

The USF ILL department first focused on processes that were wholly internal in order to 
RUNNING HEAD: Invisible Employee

not blindly impact other library departments, or ILLiad sites, to which it was connected. Initial changes to daily processes were made specifically to decrease staff effort on tasks that the department as a whole decided were superfluous, such as:

- Auto-routing requests out of a local unfilled queue when local and non-local unfilled requests were handled in the same way

- Turning on trusted sender for all deliveries that came through Odyssey so that article deliveries would go directly to the patron without staff review

- Auto-routing requests to the general cancellation queue when they had been cancelled by the customer prior to being processed in any way

- Auto-routing requests out of shipping label printing when making use of a local courier

- Auto-routing requests for materials older than five years out of the copyright clearance queue

Unmediated processing using OCLC's Direct Request was also programmed into the ILLiad system. Requests with an identifying number like OCLC or ISxN would be sent automatically to OCLC as long as the request fit certain parameters in the Direct Request profile. With the addition of the RAPID service, all possible automations were incorporated to make the addition of RAPID most seamless to staff. This included redirecting those requests that that had identifying numbers like OCLC or ISSN from Direct Request to RAPID, automatically routing requests returned by RAPID as available in our local collection to the document delivery queues for processing. If requests returned from RAPID unfilled they were automatically sent out to libraries via Direct Request. When interlibrary loan incorporated a 
RUNNING HEAD: Invisible Employee

purchase on demand (POD) program both the routing rules and Direct Request profiles were altered so that requests fitting the POD criteria would be routed out of normal processing so staff could make more considerate evaluations of them.

Eventually, USF Tampa library interlibrary loan was relying on 21 routing rules to supplement staff action on incoming interlibrary loan requests. When training or troubleshooting request problems, the path of a request had changed so much that the documentation provided by Atlas, the creator of ILLiad, was no longer completely relevant to the department. An internal step by step manual was drafted that included notes and warnings on what routing rules were enacted at any one time. All the routing rules used by the department worked when requests were moved from queue to queue by patron submission, system status update, or staff action. USF did not employ the more sophisticated server side add-ons developed by the IDS project to check material availability on incoming lending requests (IDS Project, 2017) due to a continuing project to realign local holdings with OCLC holdings.

The most effective set of routing rules concerned automated sending of requests via RAPID ILL or Direct Request with OCLC. Patron requests that included identifying numbers, like OCLC or ISxN, could be automatically sent to potential lenders. Additionally, many of the library's databases and searchable indexes automatically included this information via the Open URL connection to the interlibrary loan request pages. Patron requests made via a 'request from interlibrary loan' button in a library database would also be automatically sent out. The first step in creating this automated sending was created a Direct Request profile. Because the Purchase on Demand program that USF operated attempted to buy recent publications, recent 
RUNNING HEAD: Invisible Employee

publishing years were excluded from the direct request rule. USF's Direct Request profile for loans included the criteria:

- items published between three and 120 years ago

- unspecified request sources, patron statuses and patron departments

- Route to review for duplicate, held at institution or institutional library holdings group

- Minimum of two lenders in string

The Direct Request rule for articles was similar except that it was set to send with only one lender in string. This was decided after conversations with colleagues in the state and a review of past requests showed a high percentage of borrowing requests were filled at the first library queried. After establishing the Direct Request profiles, routing rules were added to send incoming article requests with OCLC or ISxN numbers directly to RAPID ILL from the Copyright Clearance queue, if over five years old, or directly from the Awaiting Request Processing queue after they had been reviewed by staff in the Copyright Clearance queue. If RAPID ILL returned the request because the library owned the material, the request would be send to the Document Delivery queues with the call number and location supplied by the RAPID ILL request look-up. If RAPID ILL returned the request unfilled or due to finding no match the request would be automatically routed to OCLC's Direct Request sending. Likewise, all loan requests would be automatically sent from the Awaiting Request Processing queue to OCLC's Direct Request sending if they included the identifying numbers.

The bulk of the routing rules and automated sending at USF was established in the 2011 academic year. Special care was taken not to stack routing rules, that is, not to have any sequence where a routing rule would move a request to a queue where another routing rule 
RUNNING HEAD: Invisible Employee

was intended to move the request again. Since routing rules require staff, patron, or system action to trigger, the second, and any subsequent, rule in a stacked string would not work (Atlas, 2016). For example, if an article request were moved by a rule that automatically moved all article requests over five years of age from the Copyright Clearance queue to the Awaiting Request Processing queue, it would not be automatically moved from Awaiting Request Processing to Awaiting RAPID ILL sending without ILL staff opening the request. To make RAPID ILL sending as seamless as possible, two rules were established on the Copyright Clearance queue: one to move those requests over five years of age with an OCLC or ISxN to the RAPID sending queue, and one to move those requests over five years of age without any OCLC or ISxN numbers to the Awaiting Request Processing queue. Additionally, rules were carefully written so that no two rules could work on the same request at any one time and that no rule could work on the same request twice, to avoid system errors and the possibility of a request looping continuously. For example, a routing rule in the Awaiting Unfilled Processing queue automatically moved article requests that were unfilled in RAPID to Direct Request sending. The rule specifically looked for the 'RAPID' message in the lending string in order to differentiate these requests from other unfilled requests.

The overall goals of instituting the routing rules and eliminate excess processes were to absorb some of the increased workload with the available staff and material resources as well as improve services, with a specific focus on turnaround time. Similar to the University of Arizona, USF Tampa Library ILL was only staffed during the 8am to 5pm shift during Monday through Friday. It was hoped that automated sending of requests would extend request processing time into hours when ILL staff were absent, thereby increasing the speed at which 
RUNNING HEAD: Invisible Employee

requests were filled.

ROUTING RULES

ProcessType: Borrowing

TransactionStatus: Awaiting Copyright Clearance

MatchString: u.NVTGC = 'TPA' and (t.ISSN = " or t.ISSN is NULL) AND (t.ESPNumber = " or

t.ESPNumber is NULL) AND len(t.PhotoJournalYear)=4 and t.PhotoJournalYear < convert(varchar(6),(datepart(year,getdate())-6))

NewProcessType: Borrowing

NewTransactionStatus: Awaiting Request Processing

RuleDescription: Site specific rule to bypass copyright clearance for older articles excluding what can be sent to RAPID

ProcessType: Borrowing

TransactionStatus: Awaiting Copyright Clearance

MatchString: u.NVTGC = 'TPA' and t. RequestType = 'Article' and len(t.PhotoJournalYear)=4 and t.PhotoJournalYear < convert(varchar(6), (datepart(year,getdate())-6)) AND (t.ISSN > " OR ESPNumber > ") AND u.Cleared = 'Yes'

NewProcessType: Borrowing

NewTransactionStatus: Awaiting RAPID Request Sending

RuleDescription: Site specific rule to bypass copyright clearance for older articles and send directly to RAPID

ProcessType: Borrowing

TransactionStatus: Awaiting Request Processing

MatchString: u.NVTGC = 'TPA' and (t.ISSN > " OR t.ESPNumber > ") and t.RequestType = 'Loan' and ISNULL(LendingString, ' ')=' ' and u.Cleared = 'Yes'

NewProcessType: Borrowing

NewTransactionStatus: Awaiting Direct Request Sending

RuleDescription: Site specific rule moves all Loan requests with an entry in the ISSN field to Awaiting Direct Request Sending.

ProcessType: Borrowing

TransactionStatus: Awaiting Request Processing

MatchString: u.NVTGC = 'TPA' AND t.RequestType='Article' and (t.ISSN>" OR ESPNumber >") 
RUNNING HEAD: Invisible Employee

AND ISNULL(LendingString, ' ')=' ' AND u.Cleared = 'Yes'

NewProcessType: Borrowing

NewTransactionStatus: Awaiting RAPID Request Sending

RuleDescription: Site specific rule to auto routes article requests to RAPID articles that do not bypass copyright processing will need to be moved to the unmediated process from the 'awaiting request processing' queue.

ProcessType: Borrowing

TransactionStatus: Awaiting Request Processing

MatchString: u.NVTGC = 'TPA' and (t.ISSN > " OR t.ESPNumber > ") and t.RequestType = 'Article' and t.LendingString = 'RAPID'

NewProcessType: Borrowing

NewTransactionStatus: Awaiting Direct Request Sending

RuleDescription: Site specific rule moves article requests denied by RAPID with an ISSN or an OCLC\# To Awaiting Direct Request Sending

ProcessType: Borrowing

TransactionStatus: Awaiting Unfilled Processing

MatchString: u.NVTGC = 'TPA' and t.ISSN > " and t.LendingString = 'RAPID'

NewProcessType: Borrowing

NewTransactionStatus: Awaiting Direct Request Sending

RuleDescription: Site specific rule moves requests unfilled in RAPID directly to Direct request If a request goes to RAPID and is returned by all possible lenders as unfilled, it goes to unfilled processing

\section{RESULTS}

With the addition of the automated routing rules, the turnaround time for processing an article request was reduced by over a day on average from the 2010 academic year to the present (figure 1). Turnaround times still showed great fluctuation so an analysis was done in 2016 to illuminate actual article turnaround for the bulk of materials. 
RUNNING HEAD: Invisible Employee

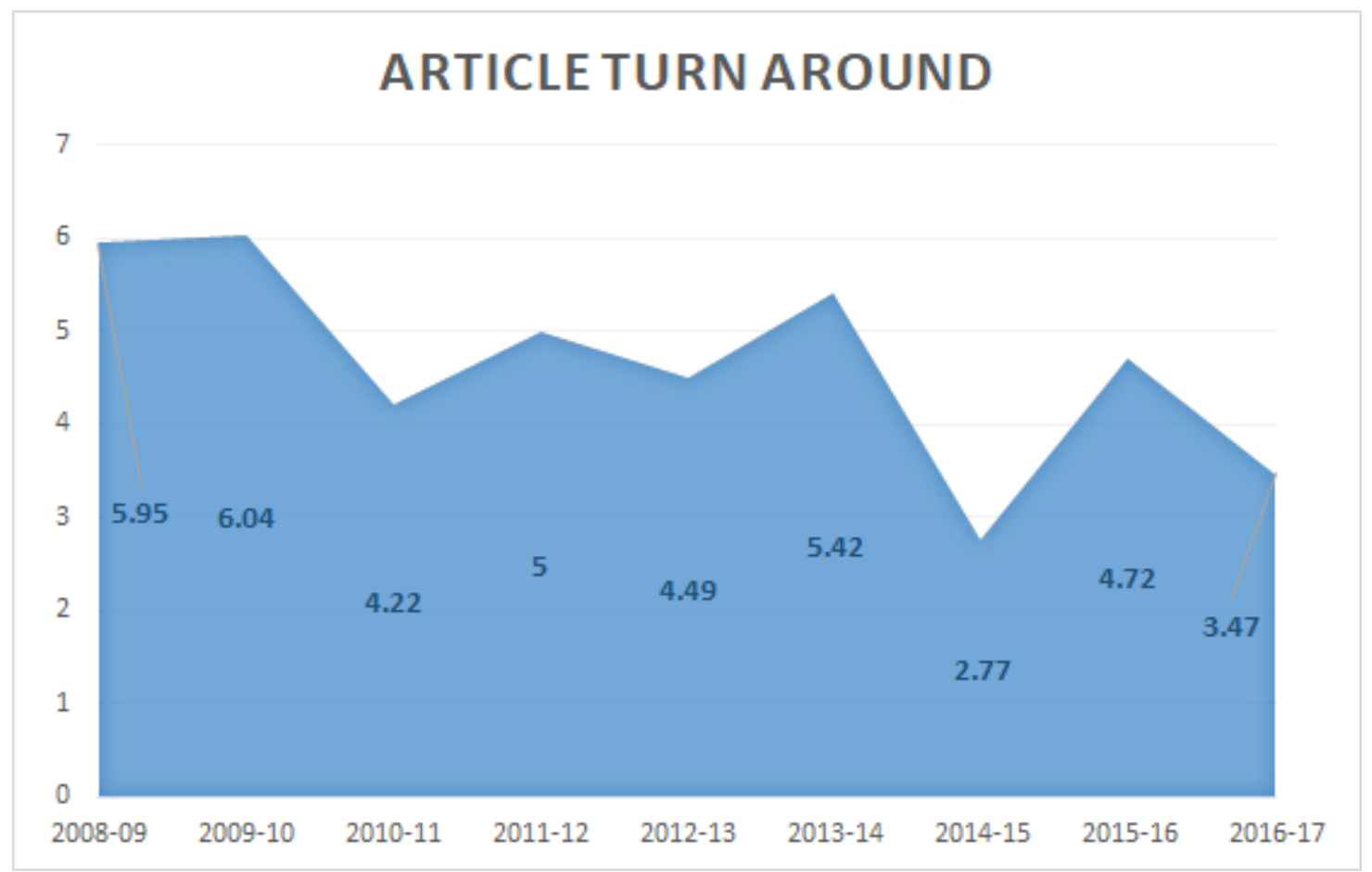

Figure 1: Average Article Turnaround

The analysis showed that nearly $60 \%$ of all articles were delivered within 24 hours

(figure 2), with over $30 \%$ being delivered in less than 12 hours. The average turnaround reported by the ILLiad web reports had been skewed by the $14 \%$ of article requests that took four or more days to fill. The majority of the requests that took longest to fill either had extensive research and processing by staff involving the patron in locating difficult to find items, or had been filled by libraries internationally who utilized physical post to send the articles. 
RUNNING HEAD: Invisible Employee

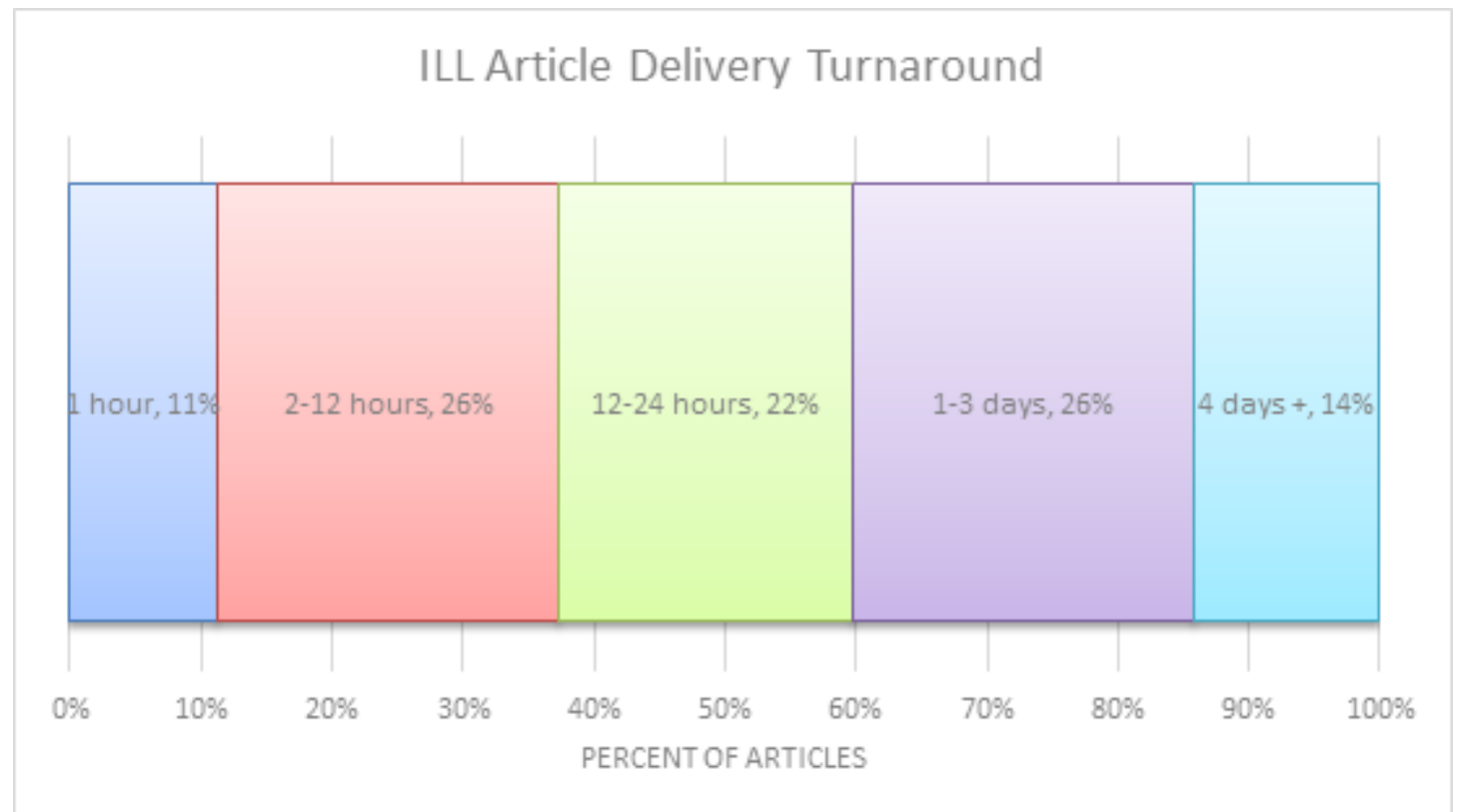

Figure 2: ILL Article Delivery Turnaround 2016

The hypothesis that the automated routing rules were helping to reduce the overall turn-around time by processing requests when the ILL department was not staffed was confirmed by the ILLiad web reports 'Request Sent by Hour' for a sample month in 2016 (figure 3). Though the bulk of processing still took place during the department's open hours, Monday - Friday $8 a m-5 p m$, requests continued to be sent to both OCLC and RAPID before and after this time frame. 
RUNNING HEAD: Invisible Employee

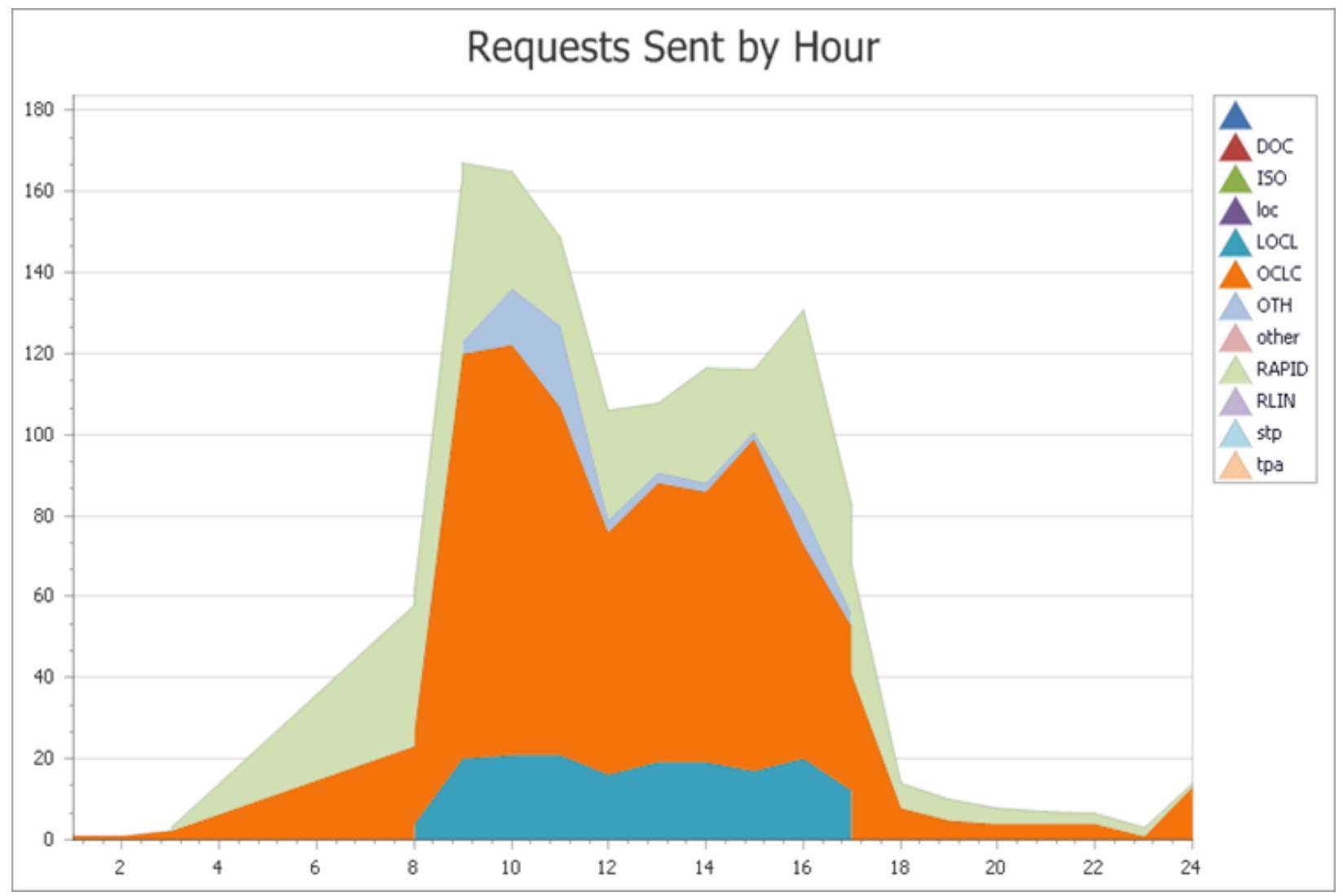

Figure 3: Requests Sent by Hour 2016

Reports were pulled via Microsoft Access to show counts of requests sent by 'System.'

The reports reveal a steady increase in automatically handled requests from the earliest established routing rules in academic year 2009 until the final line-up of routing rules in 20112012 when over thirty percent of all incoming requests were being automatically processed (figure 4). The implementation of these routing rules coincided with personnel changes that took the department from four and half full time staff, one with supervisory responsibilities, to three and half full time staff, one with supervisory responsibilities. Document delivery services were also expanded during this time, so that the decline in borrowing requests from 2014 to 2017 pictured in figure 4 did not appreciably affect the daily workload experienced by staff. System automations helped to absorb the decrease in staffing without affecting departmental 
RUNNING HEAD: Invisible Employee

performance to any large extent. Should the routing rules cease to function or the department move operations to another request processing system, the workload handled by the system would have to be considered in the planning process. Without the system acting as an invisible member of the interlibrary loan team, additional staff resources would be necessary to continue the levels of service to which library patrons had become accustomed.

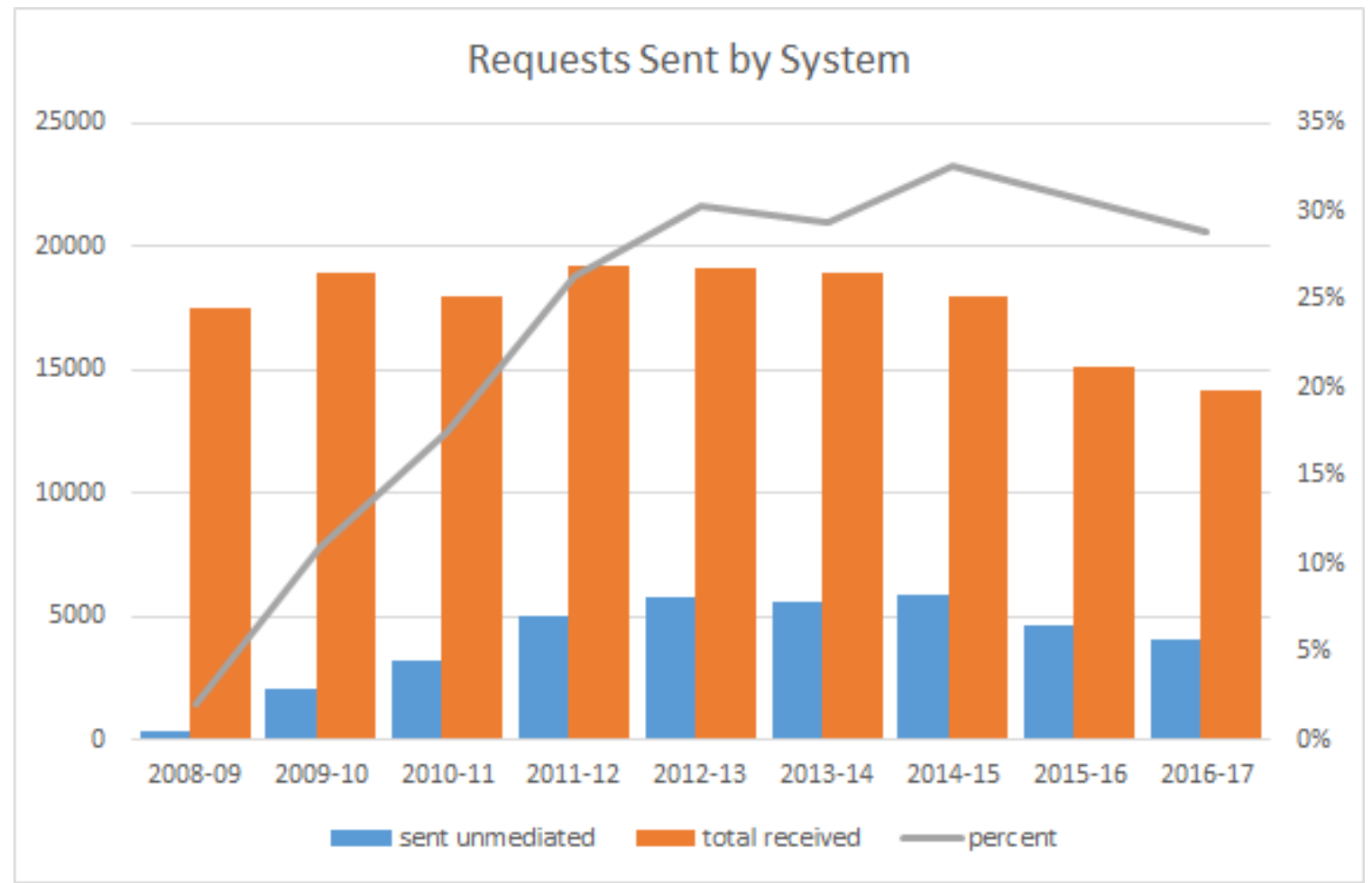

Figure 4: Requests Sent by System

\section{CONCLUSION}

Customizations to the system that allowed for the automated sending of requests peaked in 2011 with a few minor updates in the years that followed. All routing rules were programed and tested by a Library Operations Manager that has since been reorganized to a new position in another department. Should the routing rules cease to function as intended, the notes in the ILL manual will help current staff to troubleshoot issues in processing, however, failure of the rules will result in more daily work for the department. Similar to observations 
RUNNING HEAD: Invisible Employee

made by Dehmlow, interlibrary loan staff will need training to increase their specialization in the request management system in order to cope with improvements or changes to automations (2017).

This is also a concern of moving to a new interlibrary loan request management system. With the announcement that OCLC intends to move all libraries using ILLiad to a new system (OCLC, 2018), it is clear that the USF ILL department will be faced with an eventual system migration. The migration itself will require significant staff time and expertise. Additionally, the possibility that staff will be faced with $30 \%$ more requests than normal, due to the removal of automations enjoyed in ILLiad, will likely require the hiring of additional personnel in order to maintain service levels.

USF, like other libraries, exploited the customization abilities of the ILL request management system, ILLiad, to improve service and turnaround. The automations put in place during this improvement process had the additional benefit of absorbing the effects of slimming personnel in the interlibrary loan department by effectively creating an invisible team member in the system. With the possibility of changes to this invisible team member and continued budget restrictions that affect the possibility of hiring new staff, these automations can become a very real drawback very quickly. Current interlibrary loan staff have also become trained and accustomed to processes as the system handles them currently. Returning to a method of processing incoming interlibrary loan requests without the benefit of eliminating extra steps will present a learning curve as staff re-acquaint themselves with processes long since forgotten. Process improvements that rely on system capabilities are only successful as long as the system continues and remains unchanged or on a constant improvement plan. 
RUNNING HEAD: Invisible Employee

\section{REFERENCES}

Atlas (2016) Unmediated Direct Request. ILLiad 8.7 Documentation. https://prometheus.atlassys.com/display/illiad/Unmediated+Direct+Request

Dehmlow, M. m. (2017). Editorial Board Thoughts: Reinvesting in Our Traditional Personnel Through Knowledge Sharing and Training. Information Technology \& Libraries, 36(4), 46.

Fox, R. (2016). Organized chaos. Digital Library Perspectives, 32(3), 130. doi:10.1108/DLP-052016-0012

IDS Project (2017) Q. Direct Request. IDS Answers:

\section{http://idsproject.libanswers.com/faq/140943}

Kenefick, C. c., \& DeVito, J. A. (2013). Google Expectations and Interlibrary Loan: Can We Ever Be Fast Enough?. Journal Of Interlibrary Loan, Document Delivery \& Electronic Reserves, 23(3), 157-163. doi:10.1080/1072303X.2013.856365

Lepmets, M., McBride, T., \& Ras, E. (2012). Goal alignment in process improvement. The Journal Of Systems \& Software, 85(Special Issue: Agile Development), 1440-1452. doi:10.1016/j.jss.2012.01.038

Munson, K., \& Thompson, H. H. (2018). Giving Your Patrons the World: Barriers to, and the Value of, International Interlibrary Loan. Portal: Libraries \& The Academy, 18(1), 17-34.

Nozero, V. A., \& Vaughan, J. (2000). Ultilization of Process Improvement to Manage Change in an Academic Library. Journal Of Academic Librarianship, 26(6), 416.

OCLC (2018) ILLiad Overview. https://www.oclc.org/en/illiad.html.

Pritting, S., \& Jones, W. (2015). Advancements in Real-Time Availability in Interlibrary Loan. 
RUNNING HEAD: Invisible Employee

Journal Of Interlibrary Loan, Document Delivery \& Electronic Reserves, 25(1/2), 25-38. doi:10.1080/1072303X.2016.1143905

Veldof, J. R. (1999). Data driven decisions: using data to inform process changes in libraries. Library and Information Science Research, 2131-46. doi:10.1016/S0740-8188(99)800048

Voyles, J. v., Dols, L., \& Knight, E. (2009). Interlibrary Loan Meets Six Sigma: The University of Arizona Library's Success Applying Process Improvement. Journal of Interlibrary Loan, Document Delivery \& Electronic Reserves, 19(1), 75-94. 